\title{
Nocturnal hypoxaemia and hypercapnia in children with neuromuscular disorders
}

\author{
Chiara Bersanini*, Sonia Khirani ${ }^{\#}$, Adriana Ramirez*\#, Frédéric Lofaso", \\ Guillaume Aubertin*, Nicole Beydon+, Michèle Mayer ${ }^{\S}$, Kim Maincent ${ }^{\S}$, \\ Michèle Boulé ${ }^{+}$and Brigitte Fauroux ${ }^{\star}$,\#
}

ABSTRACT: The aim of the study was to identify daytime predictors of nocturnal gas exchange anomalies in children with neuromuscular disease (NMD) and normal daytime gas exchange.

Lung function tests, respiratory muscle evaluation and nocturnal gas exchange were obtained as part of routine evaluation.

We included 52 consecutive children with Duchenne muscular dystrophy $(n=20)$, spinal muscular atrophy $(n=10)$ and other NMD $(n=22) .20$ patients had nocturnal hypoxaemia, defined as minimal arterial oxygen saturation measured by pulse oximetry $\left(\mathrm{Sp}_{\mathrm{O}} \mathrm{O}_{2}\right)<\mathbf{9 0 \%}$ for $\geqslant 2 \%$ of night time, and 22 had nocturnal hypercapnia, defined as maximal transcutaneous carbon dioxide tension $\left(\mathrm{Ptc}_{\mathrm{tc}} \mathrm{CO}_{2}\right)>50 \mathrm{mmHg}$ for $\geqslant 2 \%$ of night time. Forced vital capacity and helium functional residual capacity correlated with minimal nocturnal $S p, O_{2}(p=0.009$ and $p=0.01$, respectively). Daytime $\mathrm{pH}$ correlated negatively with maximal nocturnal $\mathrm{Ptc}_{\mathrm{tc}} \mathrm{CO}_{2}(\mathrm{p}=0.005)$ and daytime arterial carbon dioxide tension $\left(\mathrm{Pa}, \mathrm{CO}_{2}\right)$ correlated with the percentage of time with a $\mathrm{Ptc}, \mathrm{CO}_{2}>50 \mathrm{mmHg}$ $(p=0.02)$. Sniff nasal inspiratory pressure correlated with minimal nocturnal $S_{p}, O_{2} \quad(p=0.02)$. Daytime $\mathrm{Pa}_{2} \mathrm{CO}_{2}$ was a weak predictor of nocturnal hypercapnia (sensitivity $80 \%$; specificity $57 \%$ ).

Daytime lung function and respiratory muscle parameters correlate poorly with nocturnal hypoxaemia and hypercapnia in children with NMD and normal daytime gas exchange, which necessitates more systematic sleep studies in these children.

KEYWORDS: Child, hypercapnia, hypoxaemia, neuromuscular disease, polysomnography, sleep

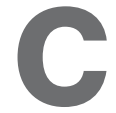

hildren with neuromuscular disease (NMD) are at risk of sleep-disordered breathing and nocturnal hypoxaemia and hypercapnia as respiratory muscle weakness progresses. The physiological drop in alveolar ventilation is exacerbated in NMD, especially during rapid eye movement sleep, a period of maximal muscle hypotonia [1]. The type of NMD may influence the onset of abnormal nocturnal gas exchange as the involvement of respiratory muscles, and in particular the diaphragm, differs among diseases [2]. Patients with NMD characterised by a predominant involvement of the diaphragm are at greater risk of nocturnal hypoventilation than patients with preserved diaphragm $[3,4]$.

Nocturnal hypoxaemia and hypercapnia should be diagnosed at an early stage to prevent the deleterious neurocognitive and cardiac consequences as well as the risk of acute respiratory failure. Indeed, noninvasive positive pressure ventilation (NPPV) has proven its efficacy in correcting abnormal nocturnal gas exchange over prolonged time periods and preventing acute respiratory exacerbations [5-9].

Unfortunately, nocturnal hypoxaemia and hypercapnia are rarely symptomatic because of their progressive onset $[10,11]$. Symptoms may be subtle and nonspecific, and frequently, children become aware of their poor sleep quality after having started NPPV. In young children, symptoms are reported by the parents, who may underestimate their presence or severity.

It is unclear when first to search for nocturnal hypoventilation $[12,13]$. If the magnitude of sleeprelated hypoventilation is related to the progression of the disease, then it might be expected to relate to daytime measures reflecting severity of respiratory muscle weakness. Identification of daytime predictors of severity of nocturnal hypoventilation could permit selection of those patients in whom the possibility of hypoventilation is sufficiently high to justify a sleep study.
AFFILIATIONS

*Paediatric Pulmonary Dept,

${ }^{\S}$ Paediatric Neurology Dept, Hôpital Armand Trousseau, AP-HP, Université Pierre et Marie Curie Paris 6 ,

\#INSERM UMR S-938, Hôpital Armand Trousseau, AP-HP,

+Lung Function Dept, Hôpital Armand Trousseau, AP-HP, Paris, and

'Physiology Dept, Hôpital Raymond Poincaré, AP-HP, Garches, France.

CORRESPONDENCE

B. Fauroux

Paediatric Pulmonary Dept

Hôpital Armand Trousseau, AP-HP

Université Pierre et Marie Curie

Paris 6

INSERM UMR S-938

28 avenue du Docteur Arnold Netter Paris

F-75012

France

E-mail: brigitte.fauroux@trs.aphp.fr

Received:

May 242011

Accepted after revision:

Sept 122011

First published online:

Dec 012011 
Vital capacity (VC) [14], forced expiratory volume in $1 \mathrm{~s}$ [15], and rapid and shallow breathing [14] have been shown to correlate with nocturnal hypercapnia in adult patients with Duchenne muscular dystrophy (DMD), whereas peak inspiratory pressure and inspiratory VC correlated with sleep-disordered breathing and the severity of nocturnal hypercapnia in children with NMD [10]. However, studies on the predictive factors of nocturnal hypoventilation in patients with NMD are scarce, and most of them have small sample sizes, or are confined to adults with one type of NMD, such as DMD [14, 15]. Importantly, respiratory muscle tests adapted to young children, such as the sniff nasal inspiratory pressure (SNIP) or gastric pressure during cough (Pgas,cough), have not been evaluated in these studies $[2,16]$.

Thus, we performed a study including children with NMD without overt daytime hypercapnia or need for NPPV during their routine annual evaluation. The aim of the study was to identify daytime parameters that could predict nocturnal gas exchange anomalies and/or respiratory events in children with NMD having daytime gas exchange within the normal range.

\section{MATERIAL AND METHODS}

For detailed information, see the online supplementary material.

\section{Patients}

All consecutive stable patients with NMD with a daytime arterial carbon dioxide tension $\left(\mathrm{Pa}_{1} \mathrm{CO}_{2}\right)<50 \mathrm{mmHg}$ were included. The institutional review board of Armand Trousseau Hospital (Paris, France) approved the study, and all parents and, if possible, patients provided written informed consent.

\section{Lung function and respiratory muscle tests}

Breathing pattern was determined from flow tracing, allowing the calculation of tidal volume $(V T)$, minute ventilation, and the rapid and shallow breathing index, which is the ratio of respiratory frequency $(f \mathrm{R})$ to $V \mathrm{~T}(f \mathrm{R} / V \mathrm{~T})$ [17].

After a period of rest, capillary arterial blood gases with determination of $\mathrm{HCO}_{3}{ }^{-}$concentration were obtained [18], followed by the functional residual capacity by helium dilution (FRCHe), forced vital capacity (FVC) [19, 20], maximal static inspiratory and expiratory pressures [21], and maximum SNIP [16].

Afterwards, an oesogastric catheter was inserted pernasally (Gaeltec, Dunvegan, UK) with assessment of the appropriate placement of the oesophageal pressure (Poes) transducer [22]. Transdiaphragmatic pressure $(P \mathrm{di})$ was obtained by subtracting the Poes signal from the gastric pressure (Pgas) signal online. Paradoxical breathing was assessed by calculating the ratio of the $P$ gas swing to the $P$ di swing $\left(\Delta P_{\text {gas }} / \Delta P_{\text {di }}\right)[23]$. The patient's inspiratory effort was assessed by measuring $P$ oes and $P$ di swings, and the oesophageal and diaphragmatic pressure-time products [24]. Dynamic lung compliance and inspiratory airway lung resistance were measured [25] as well as maximal sniff $P_{\text {oes }}$ and sniff Pdi, and Pgas,cough [26]. The diaphragmatic (Ttdi) and oesophageal (Ttoes) tension-time indexes, which estimate the endurance of the diaphragm and the global inspiratory muscles, were calculated [27].

\section{Overnight pulse oximetry and transcutaneous carbon dioxide recording}

An overnight arterial oxygen saturation measured by pulse oximetry $\left(\mathrm{Sp}_{\mathrm{p}} \mathrm{O}_{2}\right)$ and transcutaneous carbon dioxide tension
$\left(P \mathrm{tc}, \mathrm{CO}_{2}\right)$ recording was performed in room air using a combined $\mathrm{Sp}, \mathrm{O}_{2} / \mathrm{Ptc}_{\mathrm{tc}} \mathrm{CO}_{2}$ monitor (SenTec AG, Therwil, Switzerland) [28], allowing the calculation of mean and minimal $S \mathrm{p}, \mathrm{O}_{2}$, number of desaturations $\geqslant 4 \%$ per hour of recording, percentage of total night time spent with a $\mathrm{Sp}, \mathrm{O}_{2}<90 \%$, mean and maximum $\mathrm{Ptc}_{\mathrm{tc}} \mathrm{CO}_{2}$, and percentage of total night time spent with $\mathrm{Ptc}_{\mathrm{t}, \mathrm{CO}_{2}}>50 \mathrm{mmHg}$. In this diagnostic study, as the patients were not expected to have abnormal nocturnal gas exchange, nocturnal hypoxaemia was defined as a minimal $\mathrm{Sp}_{\mathrm{p}} \mathrm{O}_{2}<90 \%$ for $\geqslant 2 \%$ of night time [15] and nocturnal hypercapnia as a maximal $P_{\mathrm{tc}}, \mathrm{CO}_{2}>50 \mathrm{mmHg}$ for $\geqslant 2 \%$ of night time [29].

\section{Polysomnography}

Polysomnography (PSG) was performed in room air [30]. Obstructive apnoea was defined as a drop in thermal sensor amplitude by $\geqslant 90 \%$ of baseline for at least two respiratory cycles, with continued or increased inspiratory effort during reduced airflow. Central apnoea was defined as a drop in thermal sensor amplitude by $>0 \%$ of baseline in the absence of inspiratory effort, either with a duration $\geqslant 20 \mathrm{~s}$ or at least two missed breaths, and associated with arousal, awakening or $\geqslant 3 \%$ desaturation. Mixed apnoea was defined as a drop in thermal sensor amplitude by $\geqslant 90 \%$ of baseline for at least two respiratory cycles, initially in the absence of inspiratory effort, followed by resumption of effort during the later part of the event. Hypopnoea was defined as a drop in nasal air pressure transducer amplitude by $\geqslant 50 \%$ for a duration at least two missed breaths, associated with arousal, awakening or $\geqslant 3 \%$ desaturation [31]. Apnoea-hypopnoea index (AHI) was calculated as the sum of apnoea and hypopnoea events per hour of total sleep. Sleep-disordered breathing was defined as an AHI $>5$ events $\cdot h^{-1}$.

\section{Statistical analysis}

Data are presented as median (interquartile range). Interrelationships between lung function, respiratory muscle function, polysomnographic parameters and gas exchange were analysed using the Spearman's rank test. Group comparisons were performed using the Mann-Whitney U-test and Kruskal-Wallis rank sum test. Stepwise multiple regression analysis of rank was performed to determine the major determinant of the nocturnal dependent variable, when necessary. Predictive values of nocturnal hypoxaemia, hypercapnia and sleep-disordered breathing were computed using the receiver operating characteristic (ROC) curves. Cut-off points were calculated by bidimensional analysis at equal sensitivity to the specificity ratio. The dependent variable with the maximal area under the curve was considered to be the strongest predictor. A p-value of $<0.05$ was considered statistically significant.

\section{RESULTS \\ Patients}

52 patients were included in the study (table 1). 20 patients had DMD (age range 7-19 yrs), 10 patients had spinal muscular atrophy (age range 7-19 yrs) and 22 patients suffered from other NMD (age range 5-17 yrs): Steinert myopathy $(n=2)$, central core myopathy $(n=3)$, Ulrich myopathy $(n=1)$, Friedrich myopathy $(n=1)$, merosin deficiency $(n=2)$, facioscapulohumeral myopathy $(n=1)$, laminopathy $(n=1)$ and unknown myopathy $(n=11) .20$ patients had nocturnal hypoxaemia and 22 had nocturnal hypercapnia. Paradoxical breathing was present in one patient with DMD and three patients in the "other NMD" group. 
TABLE 1 Patients' characteristics and lung and respiratory muscle function

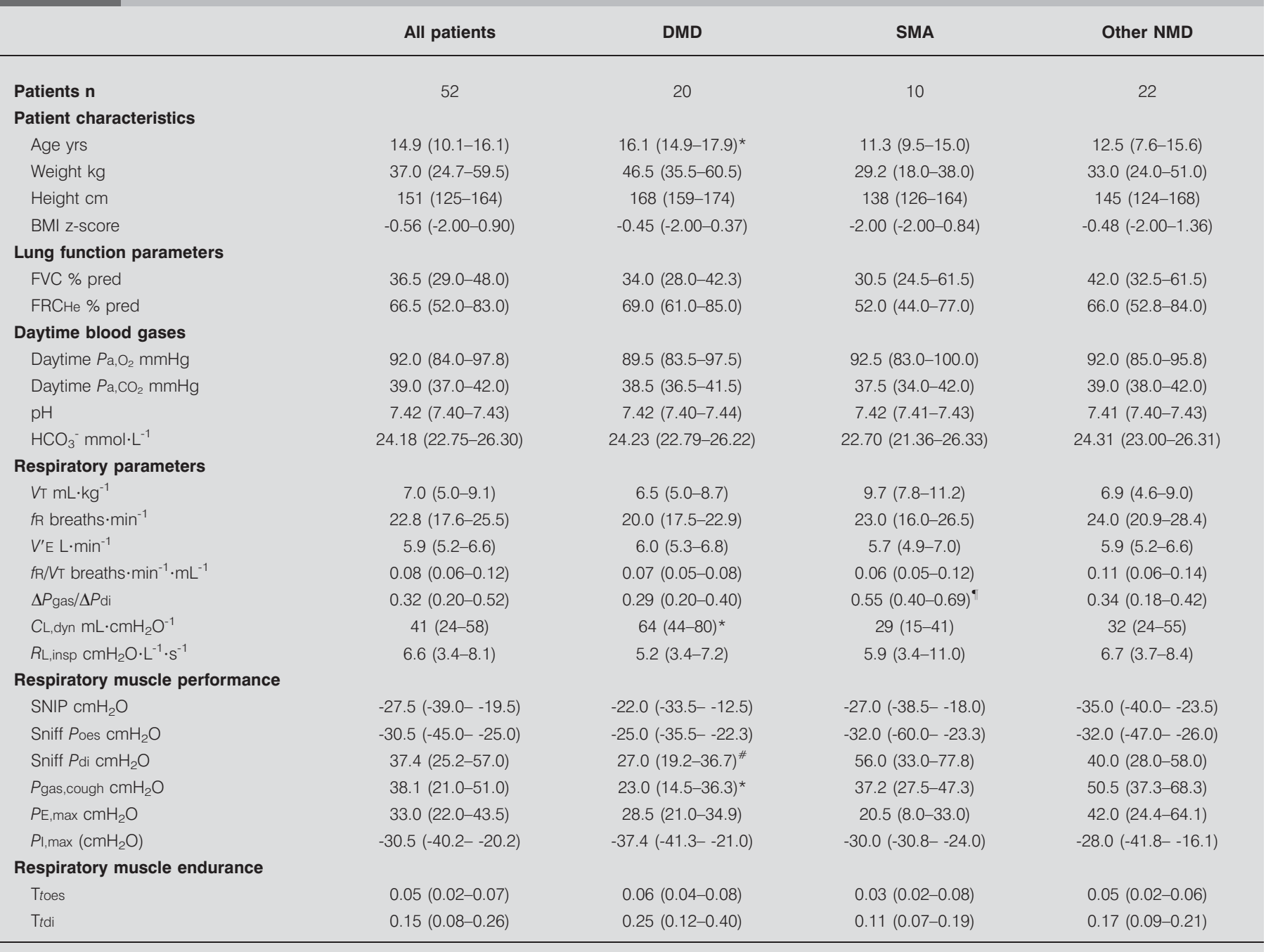

Data are presented as median (interquartile range), unless otherwise stated. DMD: Duchenne muscular dystrophy; SMA: spinal muscular atrophy; NMD: neuromuscular disease; BMI: body mass index; FVC: forced vital capacity; \% pred: \% predicted; FRCHe: functional residual capacity measured by the helium dilution technique; $\mathrm{Pa}, \mathrm{O}_{2}$ : arterial oxygen tension; $\mathrm{Pa}_{\mathrm{a}} \mathrm{CO}_{2}$ : arterial carbon dioxide tension; $\mathrm{VT}$ : tidal volume; $\mathrm{RR}$ : respiratory frequency; $V^{\prime} \mathrm{E}$ : minute ventilation; $f \mathrm{R} / \mathrm{VT}$ : rapid and shallow breathing index; $\Delta P$ gas $/ \Delta P$ di: ratio of gastric pressure swing to transdiaphragmatic pressure swing during spontaneous breathing; $C L$,dyn: dynamic lung compliance; RL,insp: inspiratory lung resistance; SNIP: sniff nasal inspiratory pressure; Poes: oesophageal pressure; Pdi: transdiaphragmatic pressure; Pgas,cough: gastric pressure during a maximal cough manoeuvre; $P E$,max: maximal static expiratory pressure; $P$ I,max: maximal static inspiratory pressure; Ttoes: tension-time index of the inspiratory muscles; Ttdi: tension-time index of the diaphragm. *: $p<0.05$ compared with SMA or other NMD; ${ }^{*}: p<0.05$ compared with SMA; ${ }^{*}: p<0.05$ compared with DMD or other NMD.

\section{Correlation of daytime parameters with nocturnal hypoxaemia and hypercapnia lung function}

FVC and FRCHe correlated positively with minimal nocturnal $S_{p}, \mathrm{O}_{2}(r=0.384(\mathrm{p}=0.009)$ and $\mathrm{r}=0.368(\mathrm{p}=0.01)$, respectively) in the total population (fig. 1). However, when the three NMD subgroups were considered separately, only FVC correlated with minimal nocturnal $\mathrm{Sp}_{\mathrm{p}} \mathrm{O}_{2}$ in the other NMD group $(r=0.695, p<0.001)$, but also with mean nocturnal $\mathrm{S}_{\mathrm{p}, \mathrm{O}_{2}}$ and the percentage of time with $\mathrm{Sp}, \mathrm{O}_{2}$ $<90 \%(\mathrm{r}=0.652(\mathrm{p}=0.002)$ and $\mathrm{r}=-0.677(\mathrm{p}<0.001)$, respectively). None of the lung function parameters correlated with nocturnal $P \mathrm{tc}, \mathrm{CO}_{2}$.

\section{Diurnal gas exchange}

Daytime $\mathrm{pH}$ correlated negatively with maximal nocturnal $P \mathrm{tc}, \mathrm{CO}_{2}$ and mean nocturnal $P_{\mathrm{tc}}, \mathrm{CO}_{2}$ in the total population $(\mathrm{r}=$ $0.400(\mathrm{p}=0.005)$ and $\mathrm{r}=-0.544(\mathrm{p}=0.002)$, respectively) and with maximal nocturnal $P_{\mathrm{tc}}, \mathrm{CO}_{2}$, mean nocturnal $P_{\mathrm{tc},} \mathrm{CO}_{2}$ and the percentage of time with $P_{\mathrm{tc},} \mathrm{CO}_{2}>50 \mathrm{mmHg}$ in the other NMD group $(\mathrm{r}=-0.477(\mathrm{p}=0.03), \mathrm{r}=-0.586(\mathrm{p}=0.02)$ and $\mathrm{r}=-0.483$ $(\mathrm{p}=0.03)$, respectively). Daytime $\mathrm{Pa}_{1}, \mathrm{CO}_{2}$ correlated with the percentage of time with $P_{\mathrm{tc},} \mathrm{CO}_{2}>50 \mathrm{mmHg}$ in the total population $(\mathrm{r}=0.345, \mathrm{p}=0.02)$ and in the other NMD group $(\mathrm{r}=0.445, \mathrm{p}=0.04)$ (fig. 2), and with mean nocturnal $P_{\mathrm{tc},}, \mathrm{CO}_{2}$ in the total population $(\mathrm{r}=0.444, \mathrm{p}=0.01)$. When the patients were 

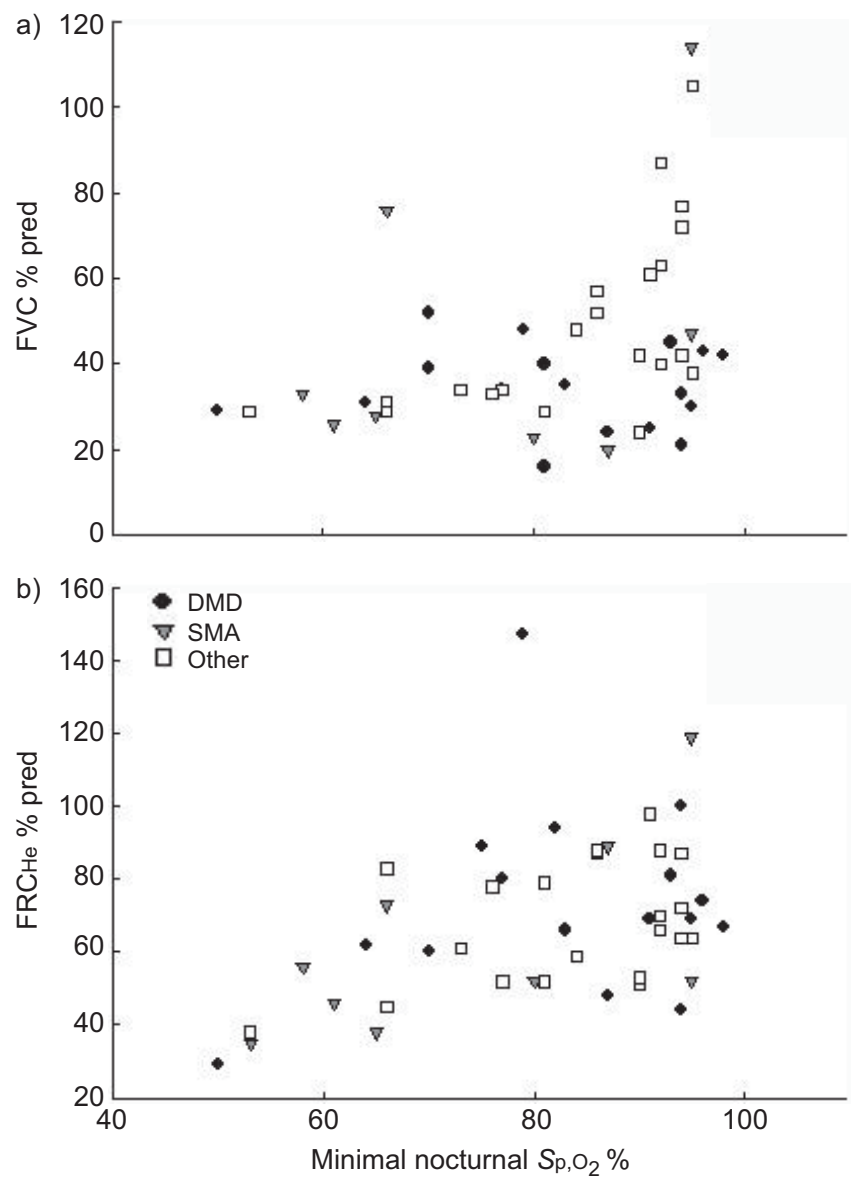

FIGURE 1. Relationship between minimal nocturnal arterial oxygen saturation measured by pulse oximetry $\left(\mathrm{Sp}, \mathrm{O}_{2}\right)$ and a) forced vital capacity ( $\left.\mathrm{FVC}\right) \%$ predicted (\% pred) and b) functional residual capacity measured by the helium diffusion technique (FRCHe) \% pred. DMD: Duchenne muscular dystrophy; SMA: spinal muscular atrophy; other: other neuromuscular disorders.

separated into those who were hypercapnic during the night and those who were not, the only parameter that differed significantly between the two groups was daytime $P a, \mathrm{CO}_{2}$, which was significantly higher in the hypercapnic patients $(p=0.009)$ (fig. 3). However, no daytime parameter differed between the patients with and without nocturnal hypoxaemia.

\section{Respiratory mechanics}

No correlation was found for any of the respiratory mechanic parameters in the total population or the subgroups.

\section{Respiratory muscles}

SNIP correlated negatively with minimal nocturnal $\mathrm{Sp}_{\mathrm{p}} \mathrm{O}_{2}$ in the total population $(\mathrm{r}=-0.358, \mathrm{p}=0.02)$ and with minimal and mean nocturnal $\mathrm{Sp}, \mathrm{O}_{2}$ in the other NMD group $(\mathrm{r}=-0.554(\mathrm{p}=0.01)$ and $\mathrm{r}=-0.632(\mathrm{p}=0.004)$, respectively). Moreover, Pgas,cough correlated positively with minimal and mean nocturnal $\mathrm{Sp}_{1} \mathrm{O}_{2}$ in the total population $(\mathrm{r}=0.316 \quad(\mathrm{p}=0.04)$ and $\mathrm{r}=0.372 \quad(\mathrm{p}=0.03)$, respectively) and with mean nocturnal $\mathrm{Sp}_{\mathrm{P}} \mathrm{O}_{2}$ in the other $\mathrm{NMD}$ group $(\mathrm{r}=0.639, \mathrm{p}=0.003)$. SNIP was the only parameter that correlated with mean nocturnal $P_{\mathrm{tc}, \mathrm{CO}_{2}}$ in the DMD group $(\mathrm{r}=0.626, \mathrm{p}=0.04)$.

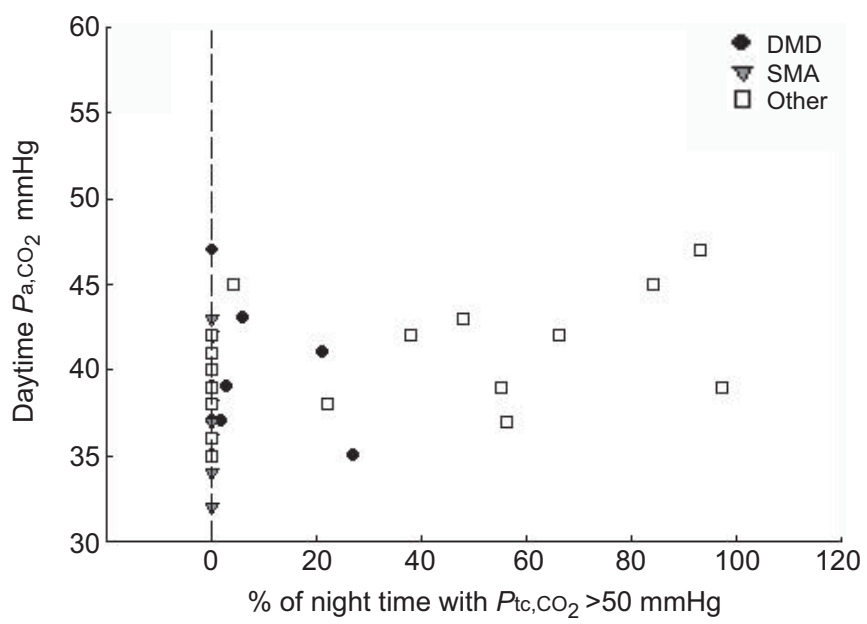

FIGURE 2. Relationship between daytime arterial carbon dioxide tension $\left(\mathrm{Pa}_{1} \mathrm{CO}_{2}\right)$ and the percentage of night time spent with a transcutaneous carbon dioxide tension $\left(\mathrm{Ptc}_{\mathrm{tc}} \mathrm{CO}_{2}\right)>50 \mathrm{mmHg}$. DMD: Duchenne muscular dystrophy; SMA spinal muscular atrophy; other: other neuromuscular disorders.

Representative data from two patients with preserved respiratory muscle strength and nocturnal hypercapnia, and two other patients with severe respiratory muscle weakness and normal nocturnal gas exchange are shown in table 2.

\section{Correlation of daytime parameters with PSG}

PSG was performed in 27 patients (table 3). Median (interquartile range) apnoea index (AI) was $1.8(0.3-4.8)$ events $\cdot \mathrm{h}^{-1}$ with a maximal value of 63 events $\cdot h^{-1}$ and median AHI was 8.6 (3.319.5) events $\cdot \mathrm{h}^{-1}$. We found that $74 \%$ of apnoeas were obstructive, $21 \%$ were central and $5 \%$ were mixed. 19 patients had an AHI $>5$ events $\cdot h^{-1}$. Daytime $\mathrm{Pa}_{2} \mathrm{CO}_{2}$ and $\mathrm{HCO}_{3}^{-}$correlated positively with AHI in the total population $(r=0.491(\mathrm{p}=0.009)$ and $\mathrm{r}=0.467$ $(p=0.01)$, respectively) and in the DMD group $(r=0.668(p=0.02)$ and $r=0.618(p=0.04)$, respectively). Lung function parameters, respiratory mechanics and respiratory muscle parameters did not correlate with $\mathrm{AI}$ or $\mathrm{AHI}$. When the patients were separated in those with an AHI $\leqslant 5$ or $>5$ events. $\mathrm{h}^{-1}$, no daytime parameter differed significantly between the two groups.

\section{Stepwise regression analysis and ROC}

Using forward stepwise regression analysis on rank, we found that FVC explained $24 \%$ of the variability of minimal nocturnal $\mathrm{Sp}, \mathrm{O}_{2}$, daytime $\mathrm{pH}$ explained $30 \%$ of the variability of mean nocturnal $\mathrm{Ptc}_{\mathrm{tc}} \mathrm{CO}_{2}$ and daytime $\mathrm{Pa}_{1}, \mathrm{CO}_{2}$ explained $26 \%$ of the variability of $\mathrm{AHI}$.

A scatter plot and ROC curve obtained for daytime $\mathrm{Pa}_{\mathrm{a}} \mathrm{CO}_{2}$ showed that a $\mathrm{Pa}, \mathrm{CO}_{2}$ value $>38 \mathrm{mmHg}$ had a $80 \%$ sensitivity but only $57 \%$ specificity for predicting nocturnal hypercapnia (fig. 3).

\section{DISCUSSION}

This study is the first to analyse lung function, daytime blood gases, respiratory mechanics, respiratory muscle strength and endurance in a large group of children with NMD in order to identify daytime parameters that could predict the need for a sleep study. Although approximately $39 \%$ and $44 \%$ of the children had nocturnal hypoxaemia and hypercapnia, respectively, and $70 \%$ had sleep-disordered breathing, no simple unique lung function or respiratory muscle parameter was 

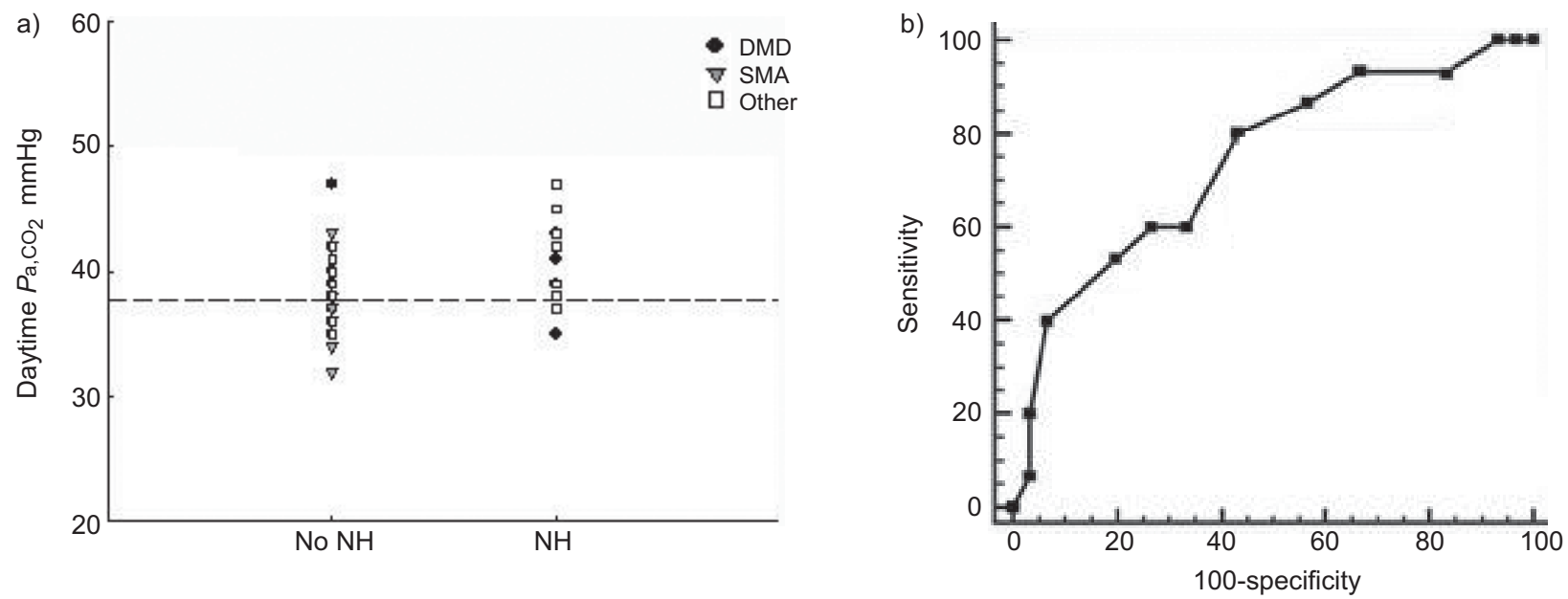

FIGURE 3. Predictive threshold of daytime arterial carbon dioxide tension $\left(\mathrm{Pa}_{1} \mathrm{CO}_{2}\right)$ computed for nocturnal hypercapnia (NH). a) Scatter plot. Dashed line indicates the optimal cut-off point for predictive value (>38 mmHg). b) Receiver operating characteristic plot. Sensitivity: $80.0 \%$; specificity: $56.7 \%$; criterion: $>38$; area under the curve: 0.74 DMD: Duchenne muscular dystrophy; SMA: spinal muscular atrophy; other: other neuromuscular disorders.

able to accurately identify patients with altered nocturnal gas exchange or sleep-disordered breathing.

Two previous studies from our group compared DMD patients with patients with other NMD, either treated or not with NPPV, and found that several tidal breathing and respiratory muscle parameters, such as $f \mathrm{R} / V \mathrm{~T}$, SNIP, Pgas,cough, and Ttoes and Ttdi were more severely impaired in the patients treated with NPPV, compared with those who did not need NPPV $[2,32]$. However, the patients treated with NPPV had more advanced disease than the patients in the present study. This was also the case for the

\begin{tabular}{|c|c|c|c|c|c|}
\hline \multirow[t]{3}{*}{ TABLE 2} & \multicolumn{5}{|c|}{$\begin{array}{l}\text { Respiratory muscles and nocturnal gas } \\
\text { exchanges measurements in four patients }\end{array}$} \\
\hline & & \multicolumn{4}{|c|}{ Patient } \\
\hline & & 1 & 2 & 3 & 4 \\
\hline \multicolumn{6}{|c|}{ Respiratory muscles } \\
\hline FVC \% pre & & 77 & 57 & 25 & 23 \\
\hline SNIP $\mathrm{cmH}_{2}$ & & -97 & -38 & -14 & -12 \\
\hline Pgas, cough & $\mathrm{nH}_{2} \mathrm{O}$ & 81 & 50 & 13 & 19 \\
\hline \multicolumn{6}{|c|}{ Nocturnal gas exchange } \\
\hline Minimal $S p$ & & 94 & 86 & 91 & 80 \\
\hline$\%$ night tim & with $\mathrm{Sp}, \mathrm{O}_{2}<90 \%$ & 0 & 0 & 0 & 0 \\
\hline Mean $\mathrm{Sp}, \mathrm{O}$ & & 99 & 96 & 95 & 97 \\
\hline Maximal $P_{t}$ & $\mathrm{CO}_{2} \mathrm{mmHg}$ & 59 & 59 & 47 & 47 \\
\hline$\%$ night tim & with $P \mathrm{tc}, \mathrm{CO}_{2}>50 \mathrm{mmHg}$ & 66 & 56 & 0 & 0 \\
\hline Mean Ptc, $\mathrm{C}$ & $\mathrm{mmHg}$ & 50 & 51 & 43 & 39 \\
\hline
\end{tabular}

Patients 1 and 2 belong to the "other neuromuscular disease" group, and are examples of preserved or moderate respiratory muscle weakness with altered nocturnal carbon dioxide tension; patients 3 (Duchenne muscular dystrophy) and 4 (spinal muscular atrophy) show a severe respiratory muscle weakness with normal nocturnal gas exchange. FVC: forced vital capacity; \% pred: \% predicted; SNIP: sniff nasal inspiratory pressure; Pgas,cough: gastric pressure during a maximal cough manoeuvre; $\mathrm{Sp}, \mathrm{O}_{2}$ : arterial oxygen saturation measured

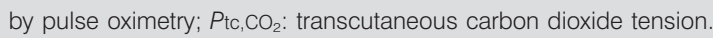

DMD patients in the study reported by TousSAINT et al. [14] who were mainly adolescents and young adults having a more advanced disease.

$\mathrm{VC}$, or inspiratory $\mathrm{VC}$, is the parameter that has been shown to correlate with nocturnal gas exchange in most studies [1, 10, 14]. This was confirmed in our study, as we found a relationship between FVC and nocturnal $\mathrm{Sp}_{\mathrm{p}} \mathrm{O}_{2}$. Moreover, $\mathrm{FRCHe}$ also correlated with nocturnal $\mathrm{Sp}_{\mathrm{p}} \mathrm{O}_{2}$. The role of forced residual capacity (FRC) is based on the fact that it is the main "oxygen reservoir". Indeed, FRC has been shown to determine apnoearelated desaturation regardless of changes in apnoea duration in adult patients with obstructive sleep apnoea [33]. In pre-term infants, a negative relationship has also been observed between FRC and the proportion of apnoeas with desaturation [34]. Moreover, it had been observed that a low FRC during the awake state is associated with a greater loss of air in the dorsal lung region during sleep [35], exposing patients to greater desaturations and apnoea during sleep [36].

Respiratory muscle parameters correlated only with nocturnal oxygenation and not with nocturnal carbon dioxide tension. This may be explained by the fact that in patients with neuromuscular weakness, the severity of nocturnal hypoxaemia is related to the postural fall in VC, suggesting that the degree of impairment of diaphragmatic function is an important determinant of nocturnal oxygenation, irrespective of involvement of other respiratory muscles [4].

As expected on a physiological basis, a correlation was observed between daytime $\mathrm{Pa}_{\mathrm{a}} \mathrm{CO}_{2}$ and nocturnal $\mathrm{Ptc}_{\mathrm{tc}} \mathrm{CO}_{2}$ in the present study and another paediatric study [10]. This study identified a $\mathrm{Pa}, \mathrm{CO}_{2}>38 \mathrm{mmHg}$ as the only daytime parameter that predicts nocturnal hypercapnia. However, its predictive power was moderate and insufficiently relevant for clinical practice. Nevertheless, our results are in agreement with those of MelLIES et al. [10], who found that $P \mathrm{a}_{1} \mathrm{CO}_{2}$ was a strong predictor of nocturnal hypercapnic hypoventilation and that a value $>40 \mathrm{mmHg}$ in NMD children should raise the suspicion of respiratory muscle fatigue and should prompt polysomnographic investigation [10]. 


\section{TABLE 3 Sleep parameters}

\begin{tabular}{|c|c|c|c|c|}
\hline Patients n & 27 & 11 & 6 & 10 \\
\hline AHI events $\cdot h^{-1}$ & $8.6(3.3-19.5)$ & $18.0(9.4-26.7)$ & $5.9(3.0-10.8)$ & $5.6(2.0-9.4)$ \\
\hline Mean $\mathrm{Sp}, \mathrm{O}_{2} \%$ & $96(94-97)$ & $94(93.5-97)$ & $94(91-97)$ & 97 (94-98) \\
\hline Minimal $\mathrm{Sp}, \mathrm{O}_{2} \%$ & $84.0(73.5-93.8)$ & $82.5(76.0-94.0)$ & $66.0(60.3-89.0)$ & $88.0(77.0-92.0)$ \\
\hline Mean $\mathrm{Ptc}, \mathrm{CO}_{2} \mathrm{mmHg}$ & $44.2(42.0-48.8)$ & $44.1(41.8-46.5)$ & $40.7(39.4-42.0)$ & $48.0(42.8-50.3)$ \\
\hline Maximal $P \mathrm{tc}, \mathrm{CO}_{2} \mathrm{mmHg}$ & $50.0(46.0-58.0)$ & $48.5(46.5-53.0)$ & $48.5(46.2-56.5)$ & $52.0(46.0-59.0)$ \\
\hline$\%$ night time with $\mathrm{Ptc}_{\mathrm{tc}} \mathrm{CO}_{2}>50 \mathrm{mmHg}$ & $0.0(0.0-9.8)$ & $0.0(0.0-4.5)$ & $0.0(0.0-0.0)$ & $0.0(0.0-55.0)$ \\
\hline
\end{tabular}

Data are presented as median (interquartile range), unless otherwise stated. DMD: Duchenne muscular dystrophy; SMA: spinal muscular atrophy; NMD: neuromuscular disease; $\mathrm{Al}$ : apnoea index; $\mathrm{AHI}$ : apnoea-hypopnoea index; $\mathrm{Sp}_{1} \mathrm{O}_{2}$ : arterial oxygen saturation measured by pulse oximetry; $\mathrm{Ptc}_{\mathrm{tc}} \mathrm{CO}_{2}$ : transcutaneous carbon dioxide tension

Several factors may explain the poor correlation between daytime parameters and nocturnal hypoventilation in our patients. First, the patients in the present study may have had too modest an impairment of their respiratory muscle performance. Indeed, none of our patients fulfilled the unanimously accepted criteria for nocturnal NPPV, i.e. a daytime $P \mathrm{a}, \mathrm{CO}_{2}>50 \mathrm{mmHg}$ and/or a history of a severe respiratory exacerbation [37, 38]. But the present study is in line with daily practice that recommends regular screening for nocturnal hypoventilation in patients in a stable state [38]. The poor correlation between the daytime lung and respiratory muscle function parameters and sleep-related parameters suggests that other factors may play a role in the preservation or deterioration of nocturnal gas exchange in children with NMD. Overweight and obesity, but also chest deformity with scoliosis, macroglossia and craniofacial deformity, cardiomyopathy, and central nervous system involvement, may all contribute to sleep-disordered breathing in patients with NMD. However, none of the patients included in the present study had severe scoliosis justifying arthrodesis or enlarged tonsils and only two patients had a body mass index z-score $>2$.

We acknowledge that our study has some limitations. There are no unanimously accepted criteria for the definition of nocturnal hypoxaemia and hypercapnia. We have arbitrarily chosen two criteria that have been used previously [15, 29], but we agree that the frequency of nocturnal hypoxaemia and hypercapnia would have been different with other criteria. Despite the fact that our study is one of the largest paediatric studies reported to date, the number of patients in each NMD subgroup was relatively small. Predictive factors that are specific for one group of NMD patients could, thus, have been missed. Invasive parameters were not available for all patients because some patients refused the oesogastric catheter and two patients had a severe nausea reflex that made the placement of the catheter too uncomfortable. The $\mathrm{AI}$ and AHI were only available for 27 patients. Because nocturnal hypoventilation is more common in patients with NMD than apnoeic events, we prioritised our search on predictors of nocturnal hypoventilation.

In conclusion, even if respiratory muscle tests correlate poorly with nocturnal gas exchange, regular monitoring of simple noninvasive tests are recommended in children with NMD.
$\mathrm{VC}$, even if not all children are able to perform a reliable and reproducible FVC manoeuvre [2], is a simple and noninvasive test that is a global indicator of respiratory muscle strength and diaphragm performance when comparing its value in the prone and supine positions. The SNIP is an easy volitional test to assess inspiratory muscle strength that has proved its feasibility and reproducibility in young children, a normal value excluding inspiratory muscle weakness, but a low value requiring the recording of $P$ oes [16]. Both tests are useful for the longitudinal monitoring of an individual patient, the indication of coughassisted techniques and perioperative NPPV in the case of scheduled surgery, such as arthrodesis. However, as these tests correlate poorly with nocturnal gas exchange, more systematic sleep studies are recommended in children with NMD.

\section{SUPPORT STATEMENT}

The research of B. Fauroux is supported by: Association Française contre les Myopathies; Vaincre la Mucoviscidose; AP-HP, INSERM; and Université Pierre et Marie Curie Paris 6.

\section{STATEMENT OF INTEREST}

None declared.

\section{REFERENCES}

1 Ragette R, Mellies U, Schwake C, et al. Patterns and predictors of sleep disordered breathing in primary myopathies. Thorax 2002; 57: 724-728.

2 Nicot F, Hart N, Forin V, et al. Respiratory muscle testing: a valuable tool for children with neuromuscular disorders. Am J Respir Crit Care Med 2006; 174: 67-74.

3 Hardie R, Harding AE, Hirsch N, et al. Diaphragmatic weakness in hereditary motor and sensory neuropathy. J Neurol Neurosurg Psychiatry 1990; 53: 348-350.

4 White JE, Drinnan MJ, Smithson AJ, et al. Respiratory muscle activity and oxygenation during sleep in patients with muscle weakness. Eur Respir J 1995; 8: 807-814.

5 Simonds A, Muntoni F, Heather S, et al. Impact of nasal ventilation on survival in hypercapnic Duchenne muscular dystrophy. Thorax 1998; 53: 949-952.

6 Simonds AK, Ward S, Heather S, et al. Outcome of paediatric domiciliary mask ventilation in neuromuscular and skeletal disease. Eur Respir J 2000; 16: 476-481. 
7 Mellies U, Ragette R, Dohna Schwake C, et al. Long-term noninvasive ventilation in children and adolescents with neuromuscular disorders. Eur Respir J 2003; 22: 631-636.

8 Dohna-Schwake C, Podlewski P, Voit T, et al. Non-invasive ventilation reduces respiratory tract infections in children with neuromuscular disorders. Pediatr Pulmonol 2008; 43: 67-71.

9 Annane D, Orlikowski D, Chevret S, et al. Nocturnal mechanical ventilation for chronic hypoventilation in patients with neuromuscular and chest wall disorders. Cochrane Database Syst Rev 2007; 4: CD001941.

10 Mellies U, Ragette R, Schwake C, et al. Daytime predictors of sleep disordered breathing in children and adolescents with neuromuscular disorders. Neuromuscul Disord 2003; 13: 123-128.

11 Kirk VG, Flemons WW, Adams C, et al. Sleep-disordered breathing in Duchenne muscular dystrophy: a preliminary study of the role of portable monitoring. Pediatr Pulmonol 2000; 29: 135-140.

12 Lofaso F, Quera-Salva MA. Polysomnography for the management of progressive neuromuscular disorders. Eur Respir J 2002; 19: 989-990.

13 Lofaso F, Fauroux B, Orlikowski D, et al. Daytime predictors of sleep-disordered breathing in neuromuscular patients to better schedule polysomnography. Eur Respir J 2011; 37: 231-232.

14 Toussaint M, Steens M, Soudon P. Lung function accurately predicts hypercapnia in patients with Duchenne muscular dystrophy. Chest 2007; 131: 368-375.

15 Hukins CA, Hillman DR. Daytime predictors of sleep hypoventilation in Duchenne muscular dystrophy. Am J Respir Crit Care Med 2000; 161: 166-170.

16 Fauroux B, Aubertin G, Cohen E, et al. Sniff nasal inspiratory pressure in children with muscular, chest wall or lung disease. Eur Respir J 2009; 33: 113-117.

17 Yang KL, Tobin MJ. A prospective study of indexes predicting the outcome of trials of weaning from mechanical ventilation. $N$ Engl J Med 1991; 324: 1445-1450.

18 Gaultier C, Boulé M, Allaire Y, et al. Determination of capillary oxygen tension in infants and children: assessment of methodology and normal values during growth. Bull Eur Physiopathol Respir 1978; 14: 287-294.

19 Quanjer PhH, Tammeling GJ, Cotes JE, et al. Lung volumes and forced expiratory flows. Report working party Standardization of Lung Function Tests European Community for Steel and Coal. Eur Respir J 1993; 6: Suppl. 16, 5s-40s.

20 Knudson RJ, Lebowitz MD, Holberg CJ, et al. Changes in the normal maximal expiratory flow-volume curve with growth and aging. Am Rev Respir Dis 1983; 127: 725-734.

21 Gaultier C, Zinman R. Maximal static pressures in healthy children. Respir Physiol Neurobiol 1983; 51: 45-61.

22 Baydur A, Behrakis PK, Zin WA, et al. A simple method for assessing the validity of the esophageal balloon technique. Am Rev Respir Dis 1982; 126: 788-791.
23 Gilbert R, Auchincloss JH Jr, Peppi D. Relationship of rib cage and abdomen motion to diaphragm function during quiet breathing. Chest 1981; 80: 607-612.

24 Sassoon CS, Light RW, Lodia R, et al. Pressure-time product during continuous positive airway pressure, pressure support ventilation and T-piece during weaning from mechanical ventilation. Am Rev Respir Dis 1991; 143: 459-475.

25 Hart N, Polkey MI, Clément A, et al. Changes in pulmonary mechanics with increasing disease severity in children and young adults with cystic fibrosis. Am J Respir Crit Care Med 2002; 166: 61-66.

26 Man WD, Kyroussis D, Fleming TA, et al. Cough gastric pressure and maximum expiratory mouth pressure in humans. Am J Respir Crit Care Med 2003; 168: 714-717.

27 Bellemare F, Grassino A. Effect of pressure and timing of contraction on human diaphragm fatigue. J Appl Physiol 1982; 53: 1190-1195.

28 Paiva R, Krivec U, Aubertin G, et al. Carbon dioxide monitoring during long-term noninvasive respiratory support in children. Intensive Care Med 2009; 35: 1068-1074.

29 Ward S, Chatwin M, Heather S, et al. Randomised controlled trial of non-invasive ventilation (NIV) for nocturnal hypoventilation in neuromuscular and chest wall disease patients with daytime normocapnia. Thorax 2005; 60: 1019-1024.

30 American Thoracic Society. Standards and indications for cardiopulmonary sleep studies in children. Am J Respir Crit Care Med 1996; 153: 866-878.

31 Iber C, Ancoli-Israel S, Chesson AL, et al. The AASM manual for the scoring of sleep and associated events. Westchester, American Academy of Sleep Medicine, 2007.

32 Fauroux B, Aubertin G, Clément A, et al. Which tests may predict the need for noninvasive ventilation in children with neuromuscular disease? Respir Med 2009; 103: 574-581.

33 Sériès F, Cormier $\mathrm{Y}$, Lampron $\mathrm{N}$, et al. Influence of lung volume in sleep apnoea. Thorax 1989; 44: 52-57.

34 Tourneux P, Léké A, Kongolo G, et al. Relationship between functional residual capacity and oxygen desaturation during short central apneic events during sleep in "late preterm" infants. Pediatr Res 2008; 64: 171-176.

35 Appelberg J, Pavlenko T, Bergman $\mathrm{H}$, et al. Lung aeration during sleep. Chest 2007; 131: 122-129.

36 Appelberg J, Nordahl G, Janson C. Lung volume and its correlation to nocturnal apnoea and desaturation. Respir Med 2000; 94: 233-239.

37 Make BJ, Hill NS, Goldberg AI, et al. Management of pediatric patients requiring long-term ventilation. Chest 1998; 113: 322S-336S.

38 Finder JD, Birnkrant D, Carl J, et al. Respiratory care of the patient with Duchenne muscular dystrophy. ATS consensus statement. Am J Respir Crit Care Med 2004; 170: 456-465. 